\title{
ASPECTOS CONTROVERSOS DO PROCESSO ELETRÔNICO
}

\author{
ALINE MARINHO BAILÃO IGLESIAS \\ JACQUELINE O. DA SILVA ZAGO DE OLIVEIRA \\ JULIANNE FREIRE MARQUES
}




\title{
ASPECTOS CONTROVERSOS DO PROCESSO ELETRÔNICO
}

\author{
Aline Marinho Bailão Iglesias ${ }^{1}$ \\ Jacqueline Orofino da Silva Zago de Oliveira² \\ Julianne Freire Marques ${ }^{3}$
}

\section{RESUMO}

O presente trabalho objetiva analisar alguns pontos controversos e conflituosos referentes ao processo eletrônico, que vem sendo implantado em todo o Poder Judiciário nos últimos anos, alcançando todas as esferas da Justiça.

Passada a discussão sobre a aceitação do sistema eletrônico, posto já ser realidade, a possibilidade de manutenção dos processos físicos mostra-se nula; é chegado o momento de estudar o sistema, com vistas à sua melhor adequação e desenvolvimento, de forma a atender todas as necessidades do Poder Judiciário.

Palavras-Chave: Processo eletrônico. Acesso à justiça. Razoável duração do processo. Pje. Home-office. Privacidade. Segurança eletrônica.

\footnotetext{
ABSTRACT

This paper aims to analyze some controversial and conflicting points regarding the electronic process, which has been implemented across the Judiciary in recent years, reaching all Justice's Institutions.

$1 \quad$ Juíza de Direito Titular da Comarca de Novo Acordo-TO. Mestranda do curso de especialização stricto sensu profissional em Prestação Jurisdicional e Direitos Humanos. E-mail: aline@tjto.jus.br.

$2 \quad 3^{\text {a }}$ Promotora de Justiça da Comarca de Colinas do Tocantins-TO. Mestranda do curso de especialização stricto sensu profissional em Prestação Jurisdicional e Direitos Humanos. E-mail: jacquesos@hotmail.com.

3 Juíza de Direito Titular da Vara da Infância e da Juventude da Comarca de Araguaína-TO. Mestranda do curso de especialização stricto sensu profissional em Prestação Jurisdicional e Direitos Humanos. E-mail: julianne@tjto.jus.br.
} 
After the discussion on the acceptance of electronic system, since it is already a reality and the possibility of maintaining the physical processes shown to be null; it comes the time to study the system, towards a better adaptation and development in order to meet all the needs of the Judiciary.

Keywords: Electronic process. Access to justice. Reasonable duration. Home-office. Privacy. Electronic security.

\section{INTRODUÇÃO}

Ao lado das Revoluções Agrícola e Industrial, a Revolução da Informação ou da Comunicação constitui o terceiro momento relevante para o progresso da humanidade, cujo elemento principal é a internet.

Com a sua popularização e crescimento, o mundo tornouse uma aldeia global em que é possível o acesso e a transmissão imediata de grande quantidade de informações, de conteúdos variados. Ou seja, por meio da internet é possível transmitir e receber informações de maneira rápida e fácil. Tornou-se um espaço amplamente democrático para divulgação de dados, quebrando o monopólio de informações.

“A internet permite a disponibilização de dados e informações a qualquer momento e por qualquer pessoa ou instituição." (COSTA, et al, 2013). Dessa forma, a globalização da informação, a diminuição das distâncias, a extinção das fronteiras e a quebra da barreira do tempo são realidades irreversíveis. As informações passaram a ser mais acessíveis com custos cada vez menores. O Poder Judiciário não poderia 
ficar alijado desse processo.

O direito enquanto ciência social deve seguir a evolução do tempo e os avanços da sociedade, sempre na busca de seus principais objetivos, quais sejam, tornar mais ágeis a tramitação dos feitos, dar credibilidade e segurança jurídica.

Nesse contexto, já sugerido pela EC nº 45, de 2004 (com a introdução do princípio da razoável duração do processo), surge a Lei $n^{0} 11.419$, de 2006, que trata da informatização dos processos judiciais. A perspectiva é no sentido de que, com o processo eletrônico, a prestação jurisdicional se torne mais célere, solucionando o problema da morosidade processual e, consequentemente, assegurando maior efetividade à prestação jurisdicional.

Assim como o avanço tecnológico é algo irreversível, também o é a implantação do processo eletrônico, em que pese a formação na área do Direito seja extremamente tradicional, o que gera resistência por parte dos operadores do direito na implantação e evolução do processo digital.

Além das consequências puramente jurídicas do processo eletrônico, sua implementação também contribui com o meio ambiente, uma vez que se deixa de utilizar o papel para a formação dos autos do processo os quais passam a ser constituídos por documentos digitais, ou seja, dados.

É inegável que o processo eletrônico tem impacto profundo nas atividades diárias dos profissionais de direito, especialmente dos magistrados, tanto na sua função técnica principal, como em suas atividades administrativas. 


\section{PROCESSO ELETRÔNICO E ACESSO À JUSTIÇA}

Um dos aspectos controversos do processo eletrônico é o acesso à justiça, direito fundamental de toda a população, expresso no artigo $5^{\circ}$, inciso XXXV, da Constituição Federal: "A lei não excluirá da apreciação do Poder Judiciário lesão ou ameaça a direito".

Luiz Guilherme Marinoni afirma que

"Uma leitura mais moderna, no entanto, faz surgir a idéia de que essa norma constitucional garante não só o direito de ação, mas a possibilidade de um acesso efetivo à justiça e, assim, um direito à tutela jurisdicional adequada, efetiva $\mathrm{e}$ tem-pestiva. Não teria cabimento entender, com efeito, que a Constituição da República garante ao cidadão que pode afirmar uma lesão ou uma ameaça a direito apenas e tão somente uma resposta, independentemente de ser ela efetiva e tempestiva. Ora se o direito de acesso à justiça é um direito fundamental, porque garantidor de todos os demais, não há como imaginar que a Constituição da República proclama apenas que todos têm direito a uma mera resposta do juiz". (MARINONI, 1999, p. 218).

$\mathrm{O}$ acesso à Justiça deve ser entendido de forma ampla, que significa o acesso de toda pessoa ao conhecimento de seus direitos e a possibilidade de exercê-los sem obstáculos, sejam econômicos ou culturais, alcançando resultados justos para seus problemas.

$\mathrm{O}$ efetivo exercício do direito consistente no acesso à justiça é requisito para a efetividade dos demais direitos previstos 
no ordenamento jurídico. Mauro Cappelletti (1992) especifica três obstáculos básicos quanto ao processo: o econômico; o organizacional; e o processual.

A primeira barreira seria o custo do processo, portanto, de natureza econômica. Surge da marginalização da classe mais pobre por se achar economicamente impedida de defender seus direitos pela via judicial, devido ao alto custo exigido por esta, e por não ter acesso à informação e representação adequada. As pessoas necessitam conhecer seus direitos para poder reivindicálos, e essa necessidade ganha importância ainda maior para o Brasil, onde as pessoas têm baixo nível educacional.

A segunda barreira (organizacional) consiste na necessidade de reivindicação dos direitos difusos, como o direito ambiental e o direito do consumidor, não por um único indivíduo, como requer o processo ordinário, mas por um ente coletivo com representatividade legítima.

Por fim, tem-se o obstáculo processual. Cappelletti (1992, p. 87) afirma: “por 'obstáculo processual' entendo o fato de que, em certas áreas ou espécies de litígios, a solução normal - o tradicional processo litigioso em juízo - pode não ser o melhor caminho para ensejar a vindicação efetiva de direitos". E aí entram meios alternativos aos procedimentos usuais, como a arbitragem, a conciliação e a mediação.

No que tange ao processo eletrônico, verifica-se que a falta de recursos financeiros e de conhecimentos técnicos, considerando-se o acesso à rede mundial de internet e a computadores, pode incidir a primeira barreira citada por Cappelletti para o acesso à justiça: a de natureza econômica. 
O Censo 2010, divulgado pelo IBGE, apontou que o país tem 14.612.183 de analfabetos, entre mais de 162 milhões de brasileiros com mais de dez anos de idade, o que representa $9,02 \%$ da população a partir dessa faixa etária.

No Tocantins, $11,88 \%$ dos habitantes com mais de dez anos são analfabetos. O percentual de pessoas que acessaram a Internet na população de 10 anos ou mais de idade, no estado do Tocantins, é de 38,2\%, segundo o PNAD 2011, que investigou o acesso à internet pela população.

Não se pode olvidar a existência de programas de inclusão digital, sendo que a Lei $\mathrm{n}^{0}$ 9.998, de 17 de agosto de 2000, institui o Fundo de Universalização dos Serviços de Telecomunicações (FUST), prevendo a utilização de seus recursos para universalização dos serviços de Telecomunicações. Os Decretos 3.753 e 3.754, ambos de 2000, estabeleceram os Planos de Metas para a Universalização de Serviços de Telecomunicações em escolas Públicas de Ensino Médio e Profissionalizante, respectivamente, prevendo que esses locais devem disponibilizar o acesso ao público de serviços de rede digitais, incluindo a internet, nas instituições públicas de ensino profissionalizante.

No entanto, extrai-se dos dados do IBGE que a população tocantinense ainda tem pouco acesso a microcomputador com internet. Dessa forma, as pessoas sem acesso a computadores ou internet, em razão de conhecimento técnico insuficiente ou de baixa renda, têm dificuldade de acessar o andamento do seu processo, e ao processo em si, com as peças processuais e depoimentos nele existentes. 
Para que o processo eletrônico esteja alinhado ao princípio da igualdade e permita o acesso à justiça, é preciso ampliar as formas de acesso à tecnologia, a fim de diminuir a diferença entre as classes sociais (Clementino, 2009), diminuindo, assim, a dificuldade de acesso à justiça para as classes de baixa renda, que surgiu pela implantação do processo eletrônico.

\section{PROCESSO ELETRÔNICO E RAZOÁVEL DURAÇÃO DO PROCESSO}

O princípio darazoável duração do processo foi introduzido na Constituição Federal com a Emenda Constitucional $n^{\circ} 45$, de 2004, que acrescentou o inciso LXXVIII ao art. $5^{\circ}$, com a seguinte redação: "a todos no âmbito judicial e administrativo, são assegurados a razoável duração do processo e os meios que garantam a celeridade de sua tramitação".

O princípio ganhou status constitucional porque se verificou que impor ao Estado o dever de prestar a Justiça não foi suficiente. É imprescindível que a prestação jurisdicional seja rápida, efetiva e adequada. A demora na prestação jurisdicional muitas vezes pode significar o sacrifício do direito da parte, além de implicar enfraquecimento político do Estado, na perda de legitimidade e credibilidade do Poder Judiciário, e gerar sentimentos de frustração naqueles que estão diretamente envolvidos na relação processual.

A partir de sua inserção no texto constitucional, foi elevado à categoria de garantia fundamental de um processo sem dilações indevidas. 
A criação do processo eletrônico vem ao encontro do que preconiza o princípio da razoável duração do processo, pois permite a economia de tempo para a prática de diversos atos tendentes a impulsionar o processo, o que, consequentemente, culmina com a solução mais rápida da demanda.

Segundo levantamento feito pelo Conselho Nacional de Justiça, do tempo gasto na tramitação do processo, 70\% é consumido com a prática de atos burocráticos, é o denominado tempo neutro que em nada contribui para a efetiva prestação jurisdicional. Com a implementação do processo eletrônico, esse tempo foi reduzido para $30 \%$.

Sobre o processo eletrônico, o art. $8^{\circ}$ da Lei $n^{\circ} 11.419$, de 2006, dispõe:

\begin{abstract}
Art. $8^{\circ}$ Os órgãos do Poder Judiciário poderão desenvolver sistemas eletrônicos de processamento de ações judiciais por meio de autos total ou parcialmente digitais, utilizando, preferencialmente, a rede mundial de computadores e acesso por meio de redes internas e externas.
\end{abstract}

Portanto, a fim de viabilizar a prática de atos que impulsionam o processo eletrônico, estes deverão ser processados por meio digital que utilize a internet (rede externa) e da intranet (rede interna). Isso permite que os envolvidos no procedimento, não só juízes, advogados e promotores, mas também os servidores do Poder Judiciário, disponham de mais tempo e possam impulsionar o processo de qualquer parte do mundo. A prática de atos processuais está disciplinada no art. 10 
do Diploma Legal acima citado, nos seguintes termos:

Art. 10. A distribuição da petição inicial e a juntada da contestação, dos recursos e das petições em geral, todos em formato digital, nos autos de processo eletrônico, podem ser feitas diretamente pelos advogados públicos e privados, sem necessidade da intervenção do cartório ou secretaria judicial, situação em que a autuação deverá se dar de forma automática, fornecendo-se recibo eletrônico de protocolo.

É possível vislumbrar ainda que o processo eletrônico permitirá a economia com pessoal. Não mais serão necessários servidores para prestar os serviços de cartorário, secretário e protocolo, estes poderão ser feitos diretamente pelos juízes, advogados e promotores.

Pode-se citar como vantagem do processo eletrônico a possibilidade de agilizar os atos processuais, a fim de tornar a prestação jurisdicional mais célere, exemplo disso são as cartas precatórias, documentos que sempre geraram atraso, e hoje circulam, em questão de segundos, por todas as comarcas interligadas no sistema.

A agilidade na tramitação dos feitos internamente é impressionante. O protocolo integrado, a interposição de petições via fax, o transporte de autos para Defensoria Pública, Ministério Público e outros órgãos federais e tantos outros empecilhos não mais existem. As audiências são feitas por meio de gravação, por sistema audiovisual. O plantão judiciário ficou facilitado, e o trabalho dos juízes, promotores e advogados pode ser realizado a qualquer momento e de qualquer local em que 
haja comunicação com a internet.

Essa agilidade conferida pelo processo eletrônico referese tão somente à velocidade de tramitação do processo, posto possibilitar a ampla disponibilidade de acesso, simultâneo, aos autos, o que antes era restringido pelo horário de funcionamento dos Fóruns. Não significa, todavia, a solução definitiva para a morosidade processual, uma vez que não houve alterações ontológicas no procedimento ordinário, referentes, sobretudo, à redução de prazos para a prática de atos processuais.

Na contramão da agilidade conferida pela implementação do processo eletrônico, encontra-se a lentidão na transmissão dos dados pelas redes externa (internet) e interna (intranet), em decorrência do atraso tecnológico. Conforme se verifica da matéria publicada no jornal Folha de São Paulo (http://www1. folha.uol.com.br/tec/2014/01/1403995-brasil-perde-quatrolugares-e-cai-para-84-em-velocidade-de-inernet.shtml), a velocidade da internet no Brasil é a $84^{\mathrm{a}}$ do mundo, mais lenta que a da Argentina, Colômbia e Iraque.

A fim de conferir verdadeira celeridade ao processo eletrônico e consequentemente, por meio dele, colocar em prática o princípio da razoável duração do processo, ao menos no que tange à sua tramitação, é necessário que haja mais investimento público na área, como forma de conferir mais rapidez ao tráfego de dados pela internet. 


\section{PROCESSO ELETRÔNICO, PUBLICIDADE E PRIVACIDADE}

Diante da rapidez com que as informações circulam mundialmente pela internet, ganha relevo o tensionamento entre o direito à publicidade do processo e à privacidade.

Ambos têm status constitucional, inexistindo hierarquia entre eles, ou seja, nenhum tem primazia absoluta sobre o outro, de modo que cada um constitui limite constitucional do outro e vice-versa.

$\mathrm{O}$ direito à privacidade surgiu com a ascensão da burguesia, no século XVIII. As atividades que eram feitas de forma comunitária passaram a se desenvolver na órbita privada. No âmbito do direito à privacidade, estão as relações pessoais do indivíduo com seus familiares e amigos; tutela de tudo o que o indivíduo não deseja que seja de conhecimento público, isto é, o direito de excluir do conhecimento de terceiros aquilo que somente a ele se refira, que diga respeito ao seu modo de ser na sua vida privada; ao passo que a intimidade constitui o núcleo mais essencial da privacidade, atinente ao que diz respeito somente à pessoa, à sua esfera mais reservada. Portanto, tem-se que a privacidade é mais ampla e engloba a intimidade.

Segundo Jean Carbonnier (apud Caldeira; Trevizan, 2013), a intimidade constitui a esfera secreta do indivíduo na qual ele tem o poder legal de evitar os demais.

Entendemos que a privacidade a que se refere o art. 5 , inciso $X$, diz respeito àquele cidadão comum, ao homem corrente, e não aos que devem 
representar a cidadania. Estes devem ter sua vida como um livro aberto. Os 'homens públicos'(...) como a própria qualificação está a indicar, são 'públicos' e não 'privados" nada podendo esconder dos que representam ou servem. (GRECO; MARTINS, 2000, p. 48)

O conceito de privacidade e intimidade é subjetivo, pois cabe a cada indivíduo determinar quais são os aspectos de sua vida que pretende impedir que chegue ao conhecimento de terceiros, Aplica-se, inclusive, ao que se divulga nas redes sociais.

A privacidade ganhou relevo nos últimos anos em decorrência de três fatores essenciais: a disseminação da informática e da internet, a qual fez com que todos passassem a manter seus dados na forma digital, facilitando sua coleta; a estruturação de bases de dados, a qual permite o cruzamento das informações fornecidas pelo usuário a cada uma delas; e a padronização de equipamentos e sistemas, a qual possibilita a aquisição de informações mantidas pelo usuário, inclusive sem o seu consentimento.

A implementação do processo eletrônico deve vir acompanhada da preocupação em assegurar que seja evitado o vazamento de dados, o que é possível por meio da adoção de chaves criptográficas, a fim de, dessa forma, assegurar o armazenamento dos dados do indivíduo.

$\mathrm{O}$ tráfego de dados processuais pela internet possibilita que todos tenham acesso a eles, e vasculhem, na rede, a vida privada de quem interessar.

O processo eletrônico também pode violar o direito ao 
esquecimento, segundo o qual, os dados devem ser conservados somente durante o período necessário para a prossecução de suas finalidades, pois os dados ficam permanentemente alocados nos servidores, passíveis de serem acessados a qualquer tempo.

Se por um lado o processo moderno deve se adequar às novas tecnologias, estas, por sua vez, não podem olvidar princípios consagrados, como o direito de personalidade, que abrange a privacidade.

Mesmo com a proteção dos dados pela administração pública, sempre haverá o risco de sua divulgação por meio da internet, em razão de possíveis invasões ao programa. Também não se pode perder de vista que, por se tratar de rede mundial de computadores, seria necessária a adoção de políticas públicas de caráter transnacional a fim de assegurar a proteção dos dados.

Por sua vez, a publicidade dos atos processuais constitui garantia inerente ao Estado Democrático de Direito, destinada a combater arbitrariedades, a proporcionar a fiscalização popular dos atos praticados por juízes, promotores e advogados no processo, além de constituir uma forma de evitar ingerências externas nas manifestações processuais dos agentes já mencionados.

A publicidade do processo é a regra e está prevista nos artigos $5^{\circ}$, LX, e $93^{\circ}$, IX, da Constituição Federal. Ambos os dispositivos ressalvam que a lei poderá restringir a publicidade dos atos processuais, a fim de defender a intimidade das partes envolvidas.

$\mathrm{O}$ art. 155 do Código de Processo Civil trata dos processos acobertados pelo segredo de justiça, ou seja, enumera 
as hipóteses em que é possível restringir a publicidade dos atos processuais, conforme autorizado pela Constituição Federal:

Art. 155. Os atos processuais são públicos. Correm, todavia, em segredo de justiça os processos: I - em que o exigir o interesse público;

Il - que dizem respeito a casamento, filiação, separação dos cônjuges, conversão desta em divórcio, alimentos e guarda de menores. (Redação dada pela Lei n ${ }^{\circ} 6.515$, de 26.12.1977)

Parágrafo único. O direito de consultar os autos e de pedir certidões de seus atos é restrito às partes e a seus procuradores. O terceiro, que demonstrar interesse jurídico, pode requerer ao juiz certidão do dispositivo da sentença, bem como de inventário e partilha resultante do desquite.

Tem-se, portanto que, excetuadas as hipóteses legais, os atos processuais são públicos. A fim de regulamentar a divulgação dos dados processuais eletrônicos na rede mundial de computadores, o Conselho Nacional de Justiça expediu a Resolução $\mathrm{n}^{\mathrm{o}}$ 121, de 5 de outubro de 2010. Merecem destaque os artigos $1^{\circ}, 2^{\circ}$ e $4^{\circ}$.

Art. $1^{\circ}$ A consulta aos dados básicos dos processos judiciais será disponibilizada na rede mundial de computadores (internet), assegurado o direito de acesso a informações processuais a toda e qualquer pessoa, independentemente de prévio cadastramento ou de demonstração de interesse.

Art. 2. ${ }^{\circ}$ Os dados básicos do processo de livre acesso são: 
I - número, classe e assuntos do processo;

II - nome das partes e de seus advogados;

III - movimentação processual;

IV - inteiro teor das decisões, sentenças, votos e acórdãos.

Art. $4 .^{\circ}$ As consultas públicas dos sistemas de tramitação e acompanhamento processual dos Tribunais e Conselhos, disponíveis na rede mundial de computadores, devem permitir a localização e identificação dos dados básicos de processo judicial segundo os seguintes critérios: (Redação dada pela Resolução no 143 , de 30.11.2011)

I - número atual ou anteriores, inclusive em outro juízo ou instâncias;

II - nomes das partes;

III - número de cadastro das partes no cadastro de contribuintes do Ministério da Fazenda;

IV - nomes dos advogados;

$\mathrm{V}$ - registro junto à Ordem dos Advogados do Brasil.

$\S 1^{\circ}$. A consulta ficará restrita às seguintes situações: (Redação dada pela Resolução $\mathrm{n}^{\circ}$ 143, de 30.11.2011)

I - ao inciso I da cabeça deste artigo, nos processo criminais, após o trânsito em julgado da decisão absolutória, da extinção da punibilidade ou do cumprimento da pena; (Redação dada pela Resolução n ${ }^{\circ} 143$, de 30.11.2011)

II - aos incisos I, IV e V da cabeça deste artigo, nos processo sujeitos à apreciação da Justiça do Trabalho. (Redação dada pela Resolução n ${ }^{\circ} 143$, de 30.11.2011)

Com esse regramento, o Conselho Nacional de Justiça 
procurou usar a proporcionalidade como forma de assegurar o equilíbrio entre duas garantias constitucionalmente asseguradas: a publicidade do processo e a privacidade do indivíduo, no intuito de compatibilizá-las sem aniquilar qualquer delas.

Vislumbra-se, assim, que a publicidade aliada ao Processo Eletrônico, desde que se tomem as cautelas necessárias à preservação da intimidade das partes quando da divulgação dos atos processuais, principalmente quanto aos processos que correm em segredo de justiça, será um grande avanço ao sistema processual e à justiça que conseguirá reduzir os custos da prestação jurisdicional oferecida aos seus jurisdicionados. (CHAVES JUNIOR, MENDES E CUNHA, 2009).

Portanto, tem-se que a publicidade dos atos processuais no processo eletrônico constitui importante elemento do Estado Democrático de Direito, mas não deve suprimir a intimidade da pessoa. Ambos precisam ser usados com proporcionalidade, para alcançar a efetividade jurisdicional esperada.

\section{DIVERGÊNCIAS NOS SISTEMAS PROCESSUAIS DOS DIVERSOS TRIBUNAIS}

Com a permissão legal para a adoção dos sistemas eletrônicos no art. $8^{\circ}$ da Lei $n^{\circ} 11.419$, de 2006, os tribunais de todo o Brasil começam a pensar essa nova realidade, e a desenvolver sistemas para o processamento de peças judiciais, ainda que parcialmente digitais. 
A lei, entretanto, não indicou um sistema único e padronizado. Assim, vários tribunais desenvolvem seus próprios sistemas:

- E-JUR - criado no TRF $1^{\text {a }}$ Região.

- PJE - criado no TRF $5^{\text {a }}$ Região.

- PROJUDI - criado no Conselho Nacional de Justiça, com expansão para mais de dezenove estados brasileiros.

- E-DOC - originário do Tribunal Superior do Trabalho com expansão para todos os Tribunais Regionais do Trabalho.

- ESCRITÓRIO DIGITAL - TRT da 9a Região.

- E-STF - programa institucional do Supremo Tribunal Federal.

- E-STJ - programa institucional do Superior Tribunal de Justiça.

- E-PROC - criado no TRF $4^{a}$ Região, hoje utilizado na Justiça de $1^{\circ}$ e $2^{\circ}$ graus do estado do Tocantins.

A falta de padronização dos sistemas processuais traz grandes entraves para a expansão dessa nova realidade. $\mathrm{O}$ principal problema é a falta de comunicação entre os sistemas.

Por exemplo, se é interposto recurso num processo dirigido aos Tribunais Superiores e estes não possuem sistema compatível com o e-Proc, o processo tem de ser todo impresso e autuado da maneira convencional. Toda a economia de papel e a agilidade, almejadas com o processo eletrônico, deixam de existir.

Duas são a saídas a serem buscadas: a interoperabilidade de todos os sistemas existentes, ou a padronização nacional do processo judicial eletrônico. 
O Conselho Nacional de Justiça estudou a situação, fez pesquisas nos tribunais e, por fim, instituiu o Sistema Processo Judicial Eletrônico como sistema informatizado de processo judicial no âmbito do Poder Judiciário, por meio da Resolução $n^{\circ} 185$, de 18/12/2013.

O Conselho Nacional de Justiça adotou o PJE como sistema nacional, em razão dos seguintes dados:

O processo judicial eletrônico (PJe), desenvolvido pelo Conselho Nacional de Justiça (CNJ) em parceria com outros órgãos da Justiça, já está sendo utilizado em 37 tribunais e seções judiciárias. O sistema está em fase de homologação em outros sete tribunais, no CNJ e no Conselho da Justiça Federal (CJF). Em outras quatro Cortes, a ferramenta está em fase de teste.

De acordo com levantamento do CNJ, o PJe já funciona nas 24 regiões da Justiça do Trabalho, nos tribunais de Justiça do Rio Grande do Sul, do Amazonas, de Mato Grosso, da Paraíba, de Pernambuco e de Minas Gerais. Na Justiça Federal, o sistema está sendo utilizado no Tribunal

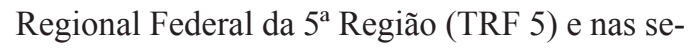
ções judiciárias de Alagoas, Ceará, Paraíba, Pernambuco, Rio Grande do Norte e Sergipe.

O Tribunal de Justiça do Estado de Pernambuco e o da Paraíba iniciaram a implantação do PJe pelo primeiro grau. Agora, o sistema está chegando ao segundo grau nos dois tribunais, já tendo sido instalalado e estando na fase de homologação, em que são feitos os últimos ajustes para que a ferramenta comece a ser utilizada plenamente.

Estão na mesma fase de instalação os tribunais de Justiça do Espírito Santo, do Ceará e do Dis- 
trito Federal e dos Territórios. No Tribunal Regional Federal da $2^{\mathrm{a}}$ Região, no Tribunal Superior Eleitoral e também no CNJ e no Conselho da Justiça Federal, o sistema eletrônico único de tramitação de processos está em fase final de implantação. (Agência CNJ de Notícias, 2012)

O PJE foi criado em 2011, mas em 2009 o Tribunal Regional Federal da $4^{\mathrm{a}}$ Região foi um dos primeiros a implantar seu próprio sistema (E-PROC) que, em pleno funcionamento, em 2010, foi comprado e adaptado para outros tribunais e juízo de $1^{\circ}$ grau, como é o caso da Justiça do Tocantins.

O juiz auxiliar da presidência do $\mathrm{CNJ}$, Paulo Cristóvão, afirma não ter sido este o sistema adotado, porque "embora já estivesse pronto e em uso, o sistema do TRF-4 não foi viável para ser replicado como padrão para os demais tribunais devido à sua complexidade e por exigir licenças pagas de software."

A $4^{\mathrm{a}}$ Região usa quatro sistemas diferentes em um só: um para petições, outro para a Central de Mandados, outro para o processo eletrônico em si e outro para a tramitação do processo em papel.” Já o PJe do CNJ é um programa aberto, que não exige qualquer licença de software. (CRISTÓVÃO, 2013).

Observando a realidade dos diversos sistemas, na Resolução optou-se por não obrigar a migração de todos os tribunais para o sistema PJE.

Pela proposta em estudo, o uso do PJe continuará facultativo, cabendo a cada tribunal decidir se 
adere ou não ao sistema. Já o modelo de interoperabilidade será obrigatório: todos os sistemas que forem desenvolvidos pelos tribunais terão necessariamente de seguir o padrão que permita o intercâmbio de informações com o PJe e outros sistemas do Judiciário, conforme determinado na Resolução Conjunta CNJ/CNMP n. 3. (Portal CNJ de Notícias).

\section{O juiz auxiliar da Presidência do CNJ esclarece:}

Não será necessário reescrever os programas. Não é preciso trocar, basta adaptar, porque o que é importante é a informação, que é o processo. Não importa qual é o sistema se ele puder trocar informação com qualquer outro, inclusive o PJe, por meio de exportação de dados (CRISTÓVÃO, 2013).

O ministro Joaquim Barbosa, presidente do CNJ e também do Supremo Tribunal Federal, em matéria veiculada no site G1, de 9 , de dezembro de 2013, demonstrou a sua preocupação com a comunicação entre os sistemas:

Não há como um tribunal se isolar e não ter como se comunicar", disse Barbosa, que proferiu palestra sobre o processo judicial eletrônico no Tribunal de Justiça de São Paulo. De acordo com o ministro, "só com a contribuição de cada tribunal, podemos alcançar os objetivos traçados pela Constituição Federal de prestação de uma Justiça minimamente aceitável. (BARBOSA, 2013). 
Respeitaram-se os sistemas já implantados, mas a interoperabilidade se mostrou obrigatória, até porque se trata de defender a própria razão de ser da implantação do sistema eletrônico, qual seja, aprimorar o sistema judicial, garantindo agilidade e economia, e o maior acesso à justiça.

\section{PROCESSO ELETRÔNICO E SEGURANÇA DOS DADOS}

Um problema que se apresenta, quando se imagina a existência do processo exclusivamente no ambiente virtual, é a desconfiança da população, em geral quanto à segurança dos dados e a garantia da autenticidade. Tal resistência dificulta a universalização do uso do processo eletrônico. E não se pode deixar de dar certa dose de razão aos desconfiados, pois os processos eletrônicos, assim como todas as informações constantes na rede mundial, estão vulneráveis a ataques de vírus e hackers, além de atos próprios de fraude processual.

Como obter a certeza da segurança dos dados? Como evitar que se apaguem despachos, sentenças, alterem-se documentos etc.?

Vários são os instrumentos utilizados pelos especialistas. Um deles é a assinatura digital. Almeida Filho (2008) cita, em sua obra, a definição do Instituto Nacional de Tecnologia da Informação:

A assinatura digital é uma modalidade de assinatura eletrônica, resultado de uma operação matemática que utiliza algoritmos de criptografia 
assimétrica e permite aferir, com segurança, a origem e a integridade do documento. A assinatura digital fica de tal modo vinculada ao documento eletrônico 'subscrito' que, ante a menor alteração neste, a assinatura se torna inválida. A técnica permite não só verificar a autoria do documento, como estabelece também uma 'imutabilidade lógica' de seu conteúdo, pois qualquer alteração do documento, como, por exemplo, a inserção de mais um espaço entre duas palavras, invalida a assinatura. (ALMEIDA FILHO, 2008).

A assinatura digital é obtida pela criptografia assimétrica. Essa expressão quer dizer, em termos simples, que se torna uma mensagem incompreensível e, para saber seu conteúdo, o interessado vai necessitar de uma chave ou segredo. Assim, nem todos terão acesso àquele conteúdo, e muito menos terão a chance de alterá-lo.

A assinatura digital é produzida a partir da certificação digital, cujo conceito é trazido por Sandro D'amato Nogueira:

É a atividade de reconhecimento em meio eletrônico que se caracteriza pelo estabelecimento de uma relação única, exclusiva e intransferível entre uma chave de criptografia e uma pessoa física, jurídica, máquina ou aplicação. Esse reconhecimento é inserido em um Certificado Digital, por uma Autoridade Certificadora. (NOGUEIRA, 2009).

O certificado digital permite comprovar a identidade de uma pessoa, empresa ou site, possibilitando transações on-line 
e troca eletrônica de documentos, de maneira segura. Além da certificação digital, os portais onde estão alocadas as informações processuais precisam adotar o denominado Gerenciamento Eletrônico de Documentos (GED). Essa tecnologia permite controlar, armazenar, compartilhar e recuperar informações existentes em documentos.

Estes são apenas alguns exemplos de instrumentos que devem ser utilizados para garantir a segurança do sistema processual eletrônico. A segurança da informação, como um todo, tem sido objeto de debate, inclusive nas Casas Legislativas, onde se discute o Marco Civil, como forma de trazer mais tranquilidade com o uso das redes.

Também tendo em vista a segurança, Luiz Carlos Delazzari apresenta as seguintes atitudes a serem tomadas:

a) backup diário - cópia de todo o processo eletrônico. É um método simples, utilizado em todos os sistemas informáticos. Seria, como já destacado, uma espécie de autos suplementares eletrônicos;

b) adoção de programas antivírus sempre atualizados, medida também simples e bastante utilizada, até mesmo em computadores domésticos. $\mathrm{O}$ vírus talvez seja o principal incômodo desde o surgimento da internet. Propaga-se através de e-mails e pode apagar arquivos, bem como alterar e roubar informações sigilosas;

c) conscientização e treinamento dos usuários, principais personagens do processo eletrônico; e d) capacitação da equipe técnica, a fim de que estejam sempre preparados para o controle permanente das informações e a adoção de medidas suficientes para evitar a invasão ao banco de da- 
dos do Poder Judiciário. (DELAZZARI, 2012).

A segurança dos dados não deveria representar objeto de resistência quanto ao processo judicial eletrônico. Isso porque se pode observar que as dificuldades enfrentadas também o são nos processos físicos. O papel é passível de várias formas de fraudes, talvez até mais que o documento virtual. Assim como deve existir constante preocupação com a segurança para processos físicos, os tribunais devem agir diuturnamente em prol da defesa dos processos digitais. Além disso, há de se observar que o processo digital tem maior durabilidade, pois não sofre as avarias trazidas pelo tempo ou ambiente, como a queima, rasgo, deformações, rasuras etc.

Não parece existir um meio absolutamente seguro, entretanto, os benefícios trazidos pelo meio eletrônico parecem superar os problemas ocasionados.

\section{PROCESSO ELETRÔNICO E HOME OFFICE}

A pré-existente discussão acerca da possibilidade de trabalho em casa, ou home office, invadiu o terreno do Poder Judiciário após a implantação dos sistemas de processo eletrônico.

O processo eletrônico permite o acesso dos servidores a todos os atos processuais, tornando praticamente desnecessária a sua presença física no Fórum para os atos de cartório. É certo que estas não são as únicas funções a serem realizadas, mas com certeza é a que consome a maior parte do tempo de serviço. 
O home office já é utilizado mesmo em tribunais, onde os processos são físicos, como o TRF-3, e também é adotado no TRF-4. Em verdade, em 2012 o Tribunal Superior do Trabalho introduziu o home office no Poder Judiciário. Ano em que a Pesquisa Nacional por Amostra de Domicílios (PNAD) concluiu que cerca de 19,5 milhões de brasileiros trabalham em casa, principalmente advindos de empresas privadas.

No dia 4 de dezembro de 2013, o presidente eleito para o biênio 2014-2015, desembargador José Renato Nalini anunciou a possibilidade de implantação do sistema de home office no Judiciário de São Paulo, o maior tribunal do país. Assim afirmou:

Eu penso, por exemplo, se possível, fazer flexibilização de horário, em lugar de fazer com que 50 mil pessoas ingressem no mesmo horário. Que as pessoas possam trabalhar às vezes em home office. O que nos interessa é a produtividade. Imagine em SP, com o tempo que as pessoas perdem no trânsito, se fosse possível usar esse tempo para lidar com mais processos? (NALINI, 2014).

A ideia divide os juristas. Nalini pretende enfatizar a produtividade, considerando as distâncias percorridas pelos servidores e as dificuldades de transporte, que poderiam, em tese, gerar trabalho a menor. Um ponto polêmico seria a necessidade de garantir atendimento ao público sem prejuízo; outro, seria a forma de fiscalizar o serviço.

Paulo Henrique dos Santos Lucon, vice-presidente do Instituto dos Advogados de São Paulo (IASP), manifestouse sobre o assunto, considerando a ideia moderna em face do 
caos do trânsito paulista, $\mathrm{Na}$ avaliação de Lucon, os meios eletrônicos devem ser utilizados em favor de todos, desde que resultados sejam cobrados do servidor, de acordo com critérios hierárquicos bem estabelecidos, tendo em vista a produtividade com qualidade. Ele defende que trabalho em casa tem de ser feito em tempo razoável. "Tal expediente deve ser igualmente célere, e não pode jamais prejudicar a prestação da Justiça. De outro modo, o atendimento ao público e aos advogados não pode ser minimamente afetado pelo home office", comenta.

O teletrabalho, ou home office, é outro ponto a se discutir com a implantação do processo eletrônico, pois a sua utilização se torna plenamente possível e pode facilitar a vida de servidores; melhorar o trânsito nas grandes cidades; diminuir os gastos do Tribunal com energia, água, telefone, e outros; além de aumentar o tempo de serviço, trazendo melhoras à prestação jurisdicional.

Veja-se o relato trazido pelo site G1.com sobre a servidora Simone Dalla-Bona do TRF-4. Ela trabalha em Los Angeles para a sede em Porto Alegre.

Ela conta que seu caso é excepcional, fruto de um pedido depois que o marido dentista conseguiu uma bolsa de dois anos em uma universidade da Califórnia. "Ou eu teria direito a uma licença não remunerada, e o tribunal ficaria com uma funcionária a menos, ou eu continuava trabalhando daqui", afirma.Simone trabalha sozinha em casa e, com a ajuda do processo eletrônico, pesquisa decisões, acha propostas para resolver os recursos e ajuda a desembargadora do gabinete onde está lotada, sempre com uma meta diária a ser cumprida. Nada de papel. "Isso 
só é possível porque está tudo informatizado. Fora toda a agilidade, espaço físico economizado do tribunal", diz.

"A única desvantagem é não ter a convivência diária. E no TRF o ambiente de trabalho é muito bom. Mas tenho vários colegas que não aceitariam. Porque têm filhos, empregada. Se eu voltar, e tiver a possibilidade, vou continuar de casa. Eu morava longe, chegava a demorar duas horas por dia no trânsito. Acho maravilhoso, muito mais produtivo, tanto para mim quanto para o tribunal", afirma a servidora. (G1.com, 2014)

O caso é excepcional, pois a regra é que os servidores não se afastem tanto do local de trabalho; no caso do TRF-4, uma distância de $80 \mathrm{~km}$. Todavia, demonstra uma possibilidade de se melhorar a produtividade e trazer qualidade de vida aos servidores e mesmo aos magistrados, e, de consequência, trazer benefícios aos Jurisdicionados.

\section{CONSIDERAÇÕES FINAIS}

O processo eletrônico deve ser considerado uma realidade nos Tribunais Brasileiros, sem possibilidade de retomada aos antigos autos físicos. Aliás, tal realidade se encontra hoje em fase de universalização e padronização, o que demonstra que já estamos em um segundo momento.

A informatização do Poder Judiciário se perfaz em prol da transparência, da maior agilidade, da modernização e ampliação do acesso à justiça.

Não obstante, o processo eletrônico é objeto de inúmeras 
críticas, algumas delas tratadas no presente trabalho, cujo estudo e preocupação, por parte dos juristas e interessados, darão origem a um sistema processual adequado.

Os benefícios são fartamente vistos, mas as dificuldades enfrentadas no dia a dia também devem ser discutidas, como forma de trazer aprimoramento a todo o sistema.

\section{REFERÊNCIAS}

ALMEIDA FILHO, José Carlos de Araújo. Processo eletrônico e teoria geral do Processo eletrônico: a informatização judicial no Brasil. Rio de Janeiro: Forense, 2008.

ALMEIDA FILHO, José Carlos de Araújo. A segurança da informação no processo eletrônico e a necessidade de regulamentaçãodaprivacidadededados.Disponívelem $<$ http:// www.egov.ufsc.br/portal/conteudo/seguran \%C3\%A7-dainforma $\% \mathrm{C} 3 \% \mathrm{~A} 7 \% \mathrm{C} 3 \% \mathrm{~A} 30-$ no-processo-eletr\%C3\%B4nicoe-necessidade-de-regulamenta $\% \mathrm{C} 3 \% \mathrm{~A} 7 \%$ C3\%A3o-daprivacidade> . Acesso em 18 de mar 2014.

CLEMENTINO, Edilberto Barbosa. Processo judicial eletrônico. Edilberto Barbosa Clementino / Curitiba: Juruá, 2009.

CRISTO, Alessandro. CNJ conclui sistema de processo judicial eletrônico. Consultor Jurídico. 09 out 2013. Disponível 
em: <http://www.conjur.com.br/2013-out-09/sistema-processoeletronico-cnj-pronto-instalacao-pais $>$. Acesso em: 18 de mar 2014.

DELAZZARI, Luiz Carlos Santana. O processo judicial eletrônico esua segurança. PortalE-gov.20dez2012.Disponível em: <http://www. egov.ufsc.br/portal/conteudo/o-processojudicial-eletr\%C3\%B4nico-e-sua-seguran $\%$ C3\%A7a-0> Acesso em: 18 de mar 2014.

D'AGOSTINO, Rosane. Barbosa pede união de tribunais para acelerar uso do processo eletrônico. Site G1.com. São Paulo, 09 dez 2013. Disponível em: http://g1.globo.com/saopaulo/noticia/2013/12/barbosa-pede-uniao-de-tribunais-paraacelerar-uso-do-processo-eletronico.html $>$ Acesso em: 18 de mar 2014.

D'AGOSTINO, Rosane. Tecnologia e falta de mobilidade estimulam home office nos tribunais. Site G1.com. São Paulo, 12 mar 2014. Disponível em: <http://g1.globo.com/concursose-emprego/noticia/2014/03/tecnologia-e-falta-de-mobilidadeestimulam-home-office-nos-tribunais.html> Acesso em: 18 de mar 2014.

EUZÉBIO, Gilson Luiz. Processo eletrônico é usado em 37 tribunais e seções judiciárias. Agência CNJ de Notícias. 20 dez 2012. Disponível em <http://www.cnj.jus.br/noticias/ cnj/22767-processo-eletronico-e-usado-em-37-tribunais-e- 
secoes-judiciarias> Acesso em 18 de mar 2014.

MARINONI, Luiz Guilher $\neg$ me. Garantia da tempestividade da tutela jurisdicional e duplo grau de jurisdição. In: CRUZ E TUCCI, José Rogério. Garantias Constitucionais do processo civil. São Paulo: RT, 1999, p. 218.

MARTINI, Renato. Inclusão digital e inclusão social. Disponível em: http://revista.ibict.br/inclusao/index.php/ inclusao/article/view/7/13> Acesso em 19 de mar 2014.

MOURA, Maísa. CNJ elabora minuta de resolução para processo eletrônico nos tribunais. Agência CNJ de Notícias. 30 ago 2013. Disponível em <http://www.cnj.jus.br/noticias/ cnj/26130-cnj-elabora-minuta-de-resolucao-para-processoeletronico-nos-tribunais> Acesso em 18 de mar 2014.

NERY, Fernando Loschiavo. A virtualização dos processos judiciais (e-proc) e a dispensabilidade de autenticação documental por tabelião. Uma análise prognóstica de suas implicações no cenário jurídico moderno. Jus Navigandi, Teresina, ano 9, n. 215, 6 fev. 2004. Disponível em: <http://jus. com.br/artigos/4795>. Acesso em 17 de mar 2014.

NERY JUNIOR, Nelson. Princípios do processo na Constituição Federal: (processo civil, penal e administrativo). São Paulo: Revista dos Tribunais, 2013. 
NOGUEIRA, Sandro D'amato. Manual de direito eletrônico. Belo Horizonte. Leme: BH Editora e Distribuidora, 2009.

OLIVEIRA, Morgana Jaques de. Aspectos polêmicos do processo eletrônico. Monografia. Curitiba, 2011.

\begin{abstract}
A polêmica em torno do home office para servidores do TJSP. Jornal GGN. 04 jan 2014. Disponível em $<$ hhttp://jornalggn. com.br/noticia /a-polemica-em-torno-do-home-office-paraservidores-do-tj-sp> Acesso em 18 de mar 2014.
\end{abstract}

Nalini quer captar recursos internacionais e implantar home office no TJ/SP. Migalhas. 05 dez 2013. Disponível em <http:// www .migalhas.com.br/ Quentes/17,MI191800,61044Nalini $+q$ uer + captar + recursos + internacionais $+\mathrm{e}+$ implantar + home + offi ce+ no> Acesso em 18 de mar 2014.

Recebido em: 15/06/2014

Aprovado em: 04/08/2014 